\title{
Programa Residência Pedagógica: Análise a partir dos Estudantes do Curso de Licenciatura em Química
}

Pedagogical Residency Program: Analysis from Undergraduate Chemistry Students

Lilian Ferreira Rocha Oséias Soares Ferreira Diego Arantes Teixeira Pires

Resumo: Almejando aperfeiçoar a formação prática nos cursos de licenciatura, foi implementado, em 2018, pela CAPES, o Programa de Residência Pedagógica, ação integrante da Política Nacional de Formação de Professores. Esse programa deve contemplar, entre outras atividades, a regência de sala de aula. Com isso, este trabalho investigou, em um curso de Licenciatura em Química, a percepção dos alunos residentes sobre o Programa Residência Pedagógica antes e depois de participarem do programa. Notou-se que a percepção dos futuros professores foi condizente com os objetivos principais do programa, mostrando que a Residência Pedagógica pode trazer uma boa experiência na Educação Básica e na formação dos estudantes.

Palavras-chave: Residência Pedagógica. Formação de professores. Docência.

Abstract: In 2018, CAPES aimed to improve practical training in undergraduate courses, and it was implemented the Pedagogical Residency Program as a part of the National Teacher Training Policy. This program should include classroom management among other activities. Thus, this work investigated the perception of resident students about the Pedagogical Residency Program before and after participating in the program of the Chemistry course. It was noted that the perception of future teachers was consistent with the main objectives of the program, showing that the Pedagogical Residence can bring a broad experience in Basic Education and in the training of students.

Keywords: Pedagogical Residence. Teacher training. Teaching.

\section{Introdução}

Um dos principais desafios enfrentados nos cursos de formação de professores no Brasil direciona-se para as dificuldades em superar a dicotomia entre teoria e prática tão presente nas matrizes curriculares dos cursos de graduação e nas práticas de muitos docentes. O estágio supervisionado é identificado como uma atividade prática obrigatória que, para maioria dos graduandos, é o único contato com a comunidade escolar. Uma análise das matrizes curriculares destes cursos superiores nos permite perceber que os componentes curriculares, muitas vezes, não se relacionam com o campo de atuação do graduando, ou seja, a sala de aula. Estas matrizes curriculares 
tornam-se então uma desordem de conhecimentos isolados. Segundo Pimenta e Lima,

Os currículos têm-se constituído em um aglomerado de disciplinas isoladas entre si, sem qualquer explicitação dos seus nexos com a realidade que se deu origem. Assim, sequer pode denominá-las teorias, pois constituem saberes disciplinares (PIMENTA; LIMA, 2004, p. 6).

Ao ter o primeiro contato com a escola, o graduando geralmente tem dificuldade em ensinar os conhecimentos teóricos apreendidos durante seu processo formativo para alunos da educação básica, pois há uma certa barreira em conseguir articular a teoria vivenciada no curso de graduação com a prática escolar e refletir sobre ela, com base na realidade da sala de aula (KASSEBOEHMER; FERREIRA, 2008). Com isso, o futuro professor acaba por imitar o modelo tradicional de ensino, que não leva em consideração a associação de teoria e prática para materialização do processo de ensino e aprendizagem, o que pode tornar a experiência do estágio não muito enriquecedora (PIMENTA; LIMA, 2017).

O estágio supervisionado deve ser um momento de reflexão sobre as ações pedagógicas (KASSEBOEHMER; FERREIRA, 2008). O ato de vivenciar a sala de aula, ver as ações e ouvir as participações pode mudar o olhar do licenciando sobre a profissão docente (PIMENTA; LIMA, 2017). Entretanto, as primeiras experiências na docência não são fáceis. É comum encontrar relatos de um grande susto com a realidade escolar no contato do licenciando com a escola quando se inicia o estágio supervisionado. Sensações de pânico, desorientação e impotência são comuns entre os graduandos de cursos de formação de professores (PIMENTA; LIMA, 2017).

Com o objetivo de aperfeiçoar a formação prática nos cursos de licenciatura, foi implementado, em 2018, pela Coordenação de Aperfeiçoamento de Pessoal de Nível Superior (CAPES), o Programa Residência Pedagógica, ação integrante da Política Nacional de Formação de Professores. Na prática os graduandos que participassem das atividades deste programa teriam validadas a carga horária do Estágio Supervisionado, obrigatório para os cursos de formação de professores. Nesse novo programa, 
existe uma maior imersão do futuro professor em sala de aula, por meio do aperfeiçoamento da formação prática nos cursos de licenciatura. Essa imersão deve contemplar, entre outras atividades, regência de sala de aula e intervenção pedagógica, acompanhadas por um professor da escola com experiência na área de ensino do licenciando e orientada por um docente da sua instituição formadora (BRASIL, 2018). O principal objetivo do programa residência pedagógica é:

A residência pedagógica consiste na imersão planejada e sistemática do aluno de licenciatura em ambiente escolar visando à vivência e experimentação de situações concretas do cotidiano escolar e da sala de aula que depois servirão de objeto de reflexão sobre a articulação entre teoria e prática. Durante e após a imersão, o residente deve ser estimulado a refletir e avaliar sobre a sua prática e relação com a profissionalização do docente escolar, para registro em relatório e contribuir para a avaliação de socialização de sua experiência como residente. Esse material deverá ser utilizado pela IES para inovar o estágio curricular de seus cursos de licenciatura (BRASIL, 2018, p. 1).

O Programa de Residência Pedagógica busca apoiar por meio de apoio financeiro, Instituições de Ensino Superior (IES) para implementação de projetos inovadores que estimulem a imprescindível articulação entre teoria e prática nos cursos de licenciatura em parceria com escolas públicas de educação básica (BRASIL, 2018). Para o graduando participar do programa, deve ter cursado, pelo menos, $50 \%$ do curso de licenciatura ou que estejam cursando a partir do $5^{\circ}$ período.

A Residência Pedagógica é pautada por quatro vertentes principais, que são:

I. Aperfeiçoar a formação dos discentes de cursos de licenciatura, por meio do desenvolvimento de projetos que fortaleçam o campo da prática e conduzam o licenciando a exercitar de forma ativa a relação entre teoria e prática profissional docente, utilizando coleta de dados e diagnóstico sobre o ensino e a aprendizagem escolar, entre outras didáticas e metodologias;

II. Induzir a reformulação do estágio supervisionado nos cursos de licenciatura, tendo por base a experiência da residência pedagógica; 
III. Fortalecer, ampliar e consolidar a relação entre a IES e a escola, promovendo sinergia entre a entidade que forma e a que recebe $o$ egresso da licenciatura e estimulando o protagonismo das redes de ensino na formação de professores;

IV. Promover a adequação dos currículos e propostas pedagógicas dos cursos de formação inicial de professores da educação básica às orientações da Base Nacional Comum Curricular (BNCC) (BRASIL, 2018, p. 1).

Este novo programa, oferecido pela CAPES, possui uma duração de 18 meses, com uma carga horária de 440 horas, sendo 60 horas para ambientação escolar, 320 horas para imersão escolar e 60 horas para elaboração de relatório, avaliação e socialização dos resultados (BRASIL, 2018). Além disso, o edital também destaca que, dentro da imersão escolar, o aluno deve cumprir uma carga horária de 100 horas para regência, que deve incluir o planejamento e execução de, pelo menos, uma intervenção pedagógica.

Em 2020, a CAPES lançou o segundo edital para o Programa Residência Pedagógica (BRASIL, 2020). As ideias principais do programa foram mantidas nesse segundo edital, com duração de 18 meses e a experiência na educação básica. Entretanto, três mudanças chamaram a atenção, por estarem diferentes do primeiro edital. A primeira foi a redução da carga horária, que passou de 440 para 414 horas. A segunda mudança foi a realização de 3 módulos ao longo do programa, cada um com duração de 6 meses e 138 horas. Essa carga horária de cada módulo deve apresentar 68 horas para a preparação dos alunos (estudo sobre os conteúdos da área e sobre metodologias de ensino, familiarização com a atividade docente por meio da ambientação na escola e da observação semiestruturada em sala de aula, elaboração de relatório do residente com o preceptor e o docente orientador, avaliação da experiência, entre outras atividades), 12 horas para elaboração de planos de aula e 40 horas de regência (BRASIL, 2020).

A terceira principal mudança observada foi a distinção entre áreas prioritárias para o programa (Alfabetização, Biologia, Ciências, Física, Língua Portuguesa, Matemática e Química) e áreas não prioritárias para o programa (Arte, Educação Física, Filosofia, Geografia, História, Informática, Língua 
Inglesa, Língua Espanhola, Sociologia, Intercultural Indígena, Educação do Campo e Pedagogia), mostrando um retrocesso educacional e um descaso com as áreas de Ciências Humanas e Sociais.

Outro ponto relevante que aparece do edital da Residência Pedagógica é que a instituição de ensino superior deve reconhecer a Residência Pedagógica como cumprimento de carga horária dos estágios supervisionados (BRASIL, 2018). Segundo as Diretrizes Curriculares Nacionais para a Formação Inicial em cursos de licenciatura, documento do Conselho Nacional de Educação (CNE), os estágios supervisionados devem apresentar uma carga horária mínima de 400 horas de atuação da educação básica e serem componentes curriculares obrigatórios (BRASIL, 2015). Com isso, tomando como base apenas os documentos oficiais, os estágios supervisionados e o programa residência pedagógica possuem objetivos principais semelhantes, sendo que a Residência apresenta uma carga horária maior.

O Instituto Federal de Educação, Ciência e Tecnologia de Goiás (IFG), campus de Luziânia, é uma das instituições de ensino superior que oferece o Programa Residência Pedagógica com a participação de 30 graduandos do curso de Licenciatura em Química, residentes em três instituições de ensino básico da região. O projeto ainda conta com três professores preceptores, cada um com 10 residentes, e um professor orientador.

O IFG possui suas próprias diretrizes curriculares para os cursos de Licenciatura (IFG, 2017). Nesse documento, os estágios supervisionados devem apresentar uma carga horária de, no mínimo, 400 horas, destacando que o estágio exige supervisão, orientação e planejamento. $O$ estágio deve apresentar quatro princípios básicos: a) a práxis na formação de professores; b) a pesquisa como modo de articulação entre teoria e prática; c) vivência em diferentes processos e espaços educativos necessários à constituição para a atividade docente e d) promover a articulação da escola campo de estágio e o IFG, compreendendo a importância da socialização das reflexões e produções provenientes de pesquisa da instituição.

No curso de Licenciatura em Química, do IFG - Campus Luziânia, os estágios supervisionados são divididos em quatro disciplinas na matriz 
curricular do curso, realizados na segunda metade do curso, com duração de quatro semestres e uma carga horária total de 405 horas (IFG, 2018).

O presente trabalho apresenta como objetivo a percepção dos residentes do curso de Licenciatura em Química do IFG campus de Luziânia em relação ao programa residência pedagógica, analisando os relatos de antes e depois que participaram do programa.

\section{Metodologia}

Utilizou-se, nesse trabalho, uma metodologia qualitativa, priorizando por uma coleta de dados descritiva, com a análise dos dados tendendo a seguir um processo indutivo (LUDKE; ANDRÉ, 1986). Adotou-se o formato de estudo de caso com três fases (exploratória, coleta de dados e análise de dados) (LUDKE; ANDRÉ, 1986). A coleta de dados foi realizada por questionários não identificados, sendo os residentes do Programa Residência Pedagógica, do Curso de Licenciatura em Química, como o público envolvido na pesquisa.

Com o início do programa residência pedagógica no curso de Licenciatura em Química do IFG, campus de Luziânia, o primeiro passo foi aplicar um questionário aos participantes antes do início das atividades, com o objetivo de analisar a percepção dos futuros residentes sobre o programa. $O$ questionário aplicado pode ser visto na Figura 1. Todos os alunos participaram de forma voluntária, sem identificação no questionário e com a anuência pelo Termo de Consentimento Livre e Esclarecido (TCLE). Nessa primeira etapa, todos os 30 alunos residentes responderam ao questionário.

Ao final do período de vigência de 18 meses do programa, foi aplicado novamente um questionário aos alunos que participaram do programa, contendo as perguntas de 5 a 13 do primeiro questionário (Figura 1), realizando apenas as adaptações dos tempos verbais das perguntas. Todos os alunos participaram de forma voluntária e sem identificação no questionário.

Nessa segunda etapa, 26 alunos residentes responderam ao questionário, sendo que 28 estudantes concluíram o programa (houve a desistência de 2 alunos ao longo do projeto). 
Figura 1: Questionário aplicado aos alunos participantes do Programa Residência Pedagógica

\section{Questionário}

1. Idade:

2. Sexo:

3. Já possui um diploma de curso superior?

( ) Sim ( ) Não

Caso sim, qual curso?

4. Já lecionou antes de ingressar na Residência Pedagógica?

( ) Sim ( ) Não

Caso sim, quais disciplinas?

Caso sim, por quanto tempo?

5. Já tinha cursado alguma disciplina de estágio curricular supervisionado em Química antes de ingressar na Residência Pedagógica?

( ) Sim ( ) Não

Caso sim, qual estágio?

6. Pretende exercer a profissão de professor?

( ) Sim ( ) Não ( ) Talvez

Justifique sua resposta:

7. Está satisfeito em ter escolhido cursar o curso de Licenciatura em Química?

( ) Sim ( ) Não ( ) Talvez

Justifique sua resposta:

8. Você acha que o Programa Residência Pedagógica poderá promover a valorização do curso de Licenciatura em Química?

( ) Sim ( ) Não ( ) Talvez

Justifique sua resposta:

9. Quais foram os principais motivos que te incentivaram a participar do Programa Residência Pedagógica?

10. A bolsa foi um dos principais motivos que te incentivou a participar do Programa Residência Pedagógica?

( ) Sim ( ) Não

11. Você acha que a Residência Pedagógica pode aperfeiçoar a formação dos futuros professores de Química?

( ) Sim ( ) Não ( ) Talvez

Justifique sua resposta:

12. Como o Programa Residência Pedagógica pode fortalecer e ampliar a relação entre o IFG e as escolas campo?

13. Você acredita que o programa Residência Pedagógica pode proporcionar aos residentes exercitar, de forma ativa, a relação entre teoria e prática profissional docente?

( ) Sim ( ) Não ( ) Talvez

Justifique sua resposta:

14. Descreva os principais motivos que te motivaram a cursar o curso de Licenciatura em Química. 


\section{Resultados e Discussão}

Com as respostas do primeiro questionário, pôde-se avaliar que dos 30 residentes, 16 eram do sexo feminino (53\%), contra 14 eram do sexo masculino (47\%). A faixa etária mais expressiva era de 18 a 24 anos (40\%), com um total de 12 pessoas. Em sequência, os residentes com idade entre 25 a 30 anos eram (27\%), 08 indivíduos, e por último, cerca de 10 residentes (33\%) tinham acima de 30 anos. Notou-se que a maioria dos residentes eram mulheres e tinham um perfil mais jovem.

A terceira pergunta questionava se o futuro residente já possuía um diploma de curso superior. 28 alunos não possuíam (93\%) e 2 alunos possuíam (7\%). Os dois alunos que possuem curso superior são graduados em Matemática.

A quarta pergunta do questionário indagava se os residentes já possuíam experiência docente antes de ingressar no programa. 27 pessoas $(90 \%)$ disseram que não, nunca tinham atuado como professor antes e 03 indivíduos (10\%) disseram que sim. As principais respostas dos alunos que já possuíam experiência docente foram:

"já lecionei 09 anos nas disciplinas de química, física e biologia";

"já dei aula em escolas de inglês por 1 ano";

"Ciência e geografia. 01 anos e 6 meses".

Embora apenas dois alunos possuam outra graduação concluída, e em Matemática, três alunos já possuem experiência em docência, sem ser na área de formação ou até sem um curso superior. Professores dando aula na educação básica sem um curso superior ou ministrando aulas em disciplinas fora da área de formação é uma realidade ainda presente no Brasil, principalmente nas regiões interioranas, onde o acesso ao ensino superior ainda é restrito, esta realidade é prática em Luziânia, interior de Goiás conforme comprovado nas pesquisas de Silva, Barbosa e Pires (2015).

Para a quinta pergunta do questionário, que indagava se o residente já havia cursado alguma disciplina de estágio supervisionado antes de ingressar na residência, 18 estudantes (60\%) responderam que sim. Desses 18 alunos, 
05 responderam já ter cursado até a disciplina de Estágio Supervisionado I, 01 aluno disse ter cursado até o Estágio Supervisionado II, 07 entrevistados cursaram até estágio Supervisionado III e 05 entrevistados cursaram todos os estágios antes de ingressar na Residência Pedagógica. Apenas 12 alunos (40\%) não haviam cursado nenhuma disciplina de Estágio antes de ingressar na residência. Para ingressar na residência, o estudante deve ter cursado mais de $50 \%$ do curso ou estar a partir do quinto semestre (BRASIL, 2018). Nota-se que alunos do sexto, sétimo e até oitavo (último) semestre do curso ingressaram no programa residência pedagógica.

No curso de Licenciatura em Química, muitos alunos chegam ao oitavo semestre sem concluir muitas disciplinas, devido ao alto índice de reprovação em algumas disciplinas. Com isso, havia alunos que já haviam cursado o oitavo semestre e, consequentemente, o último estágio, e mesmo assim estavam devendo disciplinas para os próximos 03 semestres, o que permitia a participação na Residência, mesmo já tendo finalizado todos os estágios supervisionados. Este fato mostra que a maioria dos alunos residentes estão fora do fluxo curricular, indicando que já reprovaram em alguma disciplina ao longo do curso, fato específico para o curso de Química da instituição em estudo.

Analisando a sexta pergunta, quando questionado se antes de participar da residência o graduando pretendia exercer a profissão de professor, a metade dos entrevistados (15) responderam que sim, 2 entrevistados $(7 \%)$ responderam que não queriam exercer a profissão e 13 deles (43\%) responderam que talvez. As justificativas que os levaram a responder sim, em grande maioria, disseram que podem contribuir com a carreira docente, como nas respostas:

\footnotetext{
"Sim, mesmo com todos os problemas enfrentados pelo docente em sala de aula, ainda tenho esperança que, fazendo a minha parte, posso fazer a diferença";

"Sim, acredito que a educação pode transformar a vida de um indivíduo e gostarei de ser parte disso".
} 
Para os residentes que responderam que não queriam exercer a carreira docente, esses afirmaram não ter aptidão para a profissão e porque a carreira docente estava desvalorizada, como nos dizeres:

"Não me identifico com a profissão";

"Não, a carreira docente é muito desvalorizada, por isso quero trabalhar na indústria química que será uma carreira melhor".

Quanto aos residentes que responderam que talvez seguiriam a carreira docente, foram apresentadas várias razões. Porém, a resposta que mais se sobressaiu foi que a docência não era a primeira opção de profissão, como as seguintes respostas:

"Não é a profissão que tenho prioridade em exercer, a minha maior vontade é de trabalhar na área industrial, mas se surgir uma boa oportunidade, poderei exercer a profissão de professor";

"Não é a minha primeira opção, no entanto não descarto a possibilidade. Entendo que em qualquer profissão existirão desafios, mas a carreira de professor não é fácil, ainda mais para pessoas como eu que não tem facilidade de lidar com o outro. Além disso, o salário não é tão atrativo para uma área que exige muito do profissional, como é o caso da docência."

Após concluírem o Programa de Residência Pedagógica, os estudantes foram perguntados novamente se pretendiam exercer a profissão de professor, e 23 residentes (88\%) responderam que sim, 1 residente (4\%) que não e 2 residentes $(8 \%)$ responderam que talvez. As principais justificativas foram:

"Sim, eu tinha minhas dúvidas, porém com a residência pude perceber que sim, mesmo tendo contratempo que são enfrentados no cotidiano escolar";

"Não, tenho como prioridade trabalhar em laboratório, pois é algo me identifico";

"Talvez, porque preciso encontrar o equilíbrio para ser um melhor professor, não quero ser mais um professor tradicional, assim como os meus, do ensino médio."

O total de alunos que pretende seguir na profissão docente passou de $50 \%$ para $88 \%$ após a participação na residência pedagógica. Este fato pode 
mostrar que os programas governamentais de incentivo à docência, como o Programa Institucional de Bolsa de Iniciação à Docência (PIBID) e Residência Pedagógica podem estimular o licenciando a ter um maior interesse para seguir a carreira docente. Pelo relato de alguns residentes que participaram desta pesquisa, esta profissão ainda é muito desvalorizada e desprestigiada, e Programas de Incentivo à Docência podem trazer uma certa valorização para a profissão.

Para a sétima pergunta do questionário (você está satisfeito em ter escolhido cursar o curso de Licenciatura em Química?), antes de iniciar as atividades da residência, 26 entrevistados (87\%) responderam que sim, estavam satisfeitos, contra 01 entrevistado (3\%) respondeu que não estava satisfeito em cursar Licenciatura em Química e 03 entrevistados (10\%) responderam que talvez estavam satisfeito em fazer o curso. Algumas justificativas foram:

"Sim, a Química é um universo incrível de se estudar, porque ao passar dos anos, a tecnologia se desenvolve e a Química também";

"Não, pois acho que o curso deveria ter mais disciplinas de Química que aprofundassem em conhecimentos laboratoriais";

"Talvez, estou meio satisfeito porque sinceramente não é a minha primeira opção de curso";

"Talvez, porque eu estou ainda me adaptando ao curso de licenciatura".

Após a participação no programa, 100\% dos entrevistados disseram que estavam satisfeitos com a escolha, diferente do primeiro questionário em que 26 alunos cerca de $(87 \%)$ diziam estar satisfeito, o que mostra um aumento da satisfação em cursar a Licenciatura em Química após participar da Residência Pedagógica. As respostas de justificativa foram:

"Toda carreira tem seus percalços e na licenciatura, principalmente nos cursos voltados para educação não poderia ser diferente. $O$ que vai fazer toda diferença nessa perspectiva e o papel e a atuação do profissional em levar todo o conhecimento adquirido para o campo de atuação e dessa forma contribuir para melhoria do sistema educacional, realizando seu trabalho em conjunto com colegas de profissão 
e gestores, visando sempre o melhor para todos dos envolvidos";

"Porque é um curso que abrange um grande leque de oportunidades profissionais, trabalhando tanto na indústria quanto lecionando para o ensino médio".

Além de despertar o interesse dos alunos para a profissão docente, o

Programa de Residência Pedagógica pode ter contribuído também para melhorar o interesse dos graduandos pelo curso de Química. E este fato não se deve apenas pela experiência na regência, visto que vários alunos já haviam tido essa experiência pelo estágio supervisionado. Nesse sentido, o programa pode ter funcionado para trazer uma boa experiência aos futuros professores quanto à Educação Básica, que é um dos objetivos principais do Programa em questão (BRASIL, 2018).

Em relação a oitava pergunta, que questionava se a residência pedagógica poderia promover uma valorização do curso de Licenciatura em Química, antes da participação no programa, 26 residentes (87\%) responderam que sim, nenhum respondeu que não e 4 (13\%) responderam que talvez. Destaca-se algumas respostas:

"Sim, porque leva o futuro docente a ter uma relação mais intensa com a escola";

"Pode valorizar sim, pois o programa é uma forma de promover a excelência na formação de futuros professores. Esse contato que o graduando tem com a escola é muito importante e traz uma seriedade maior às atividades realizadas";

"Talvez, posso estar errada, mas a residência pedagógica proporcionará para nós um melhor aprofundamento, mas não afetará em nada na questão da valorização".

Analisando a mesma pergunta após a participação no programa, 25 residentes (96\%) responderam que sim, nenhum respondeu que não e 01 residente (4\%) que respondeu talvez a residência valorizava o curso. Algumas justificativas apresentadas foram:

"O programa fez com que os residentes tivessem contato com a realidade da escola e mostra o quanto é necessário que haja mais professores qualificados. Esse programa também promoveu a interação entre o residente e os profissionais da escola e dos residentes com os alunos, além de que os residentes auxiliaram muito os professores durante as aulas"; 
"Porque levou o discente direto para sala de aula, isso ajudou a ter um contato direto com os problemas diários encontrados na escola, desta forma, esse futuro professor teve a chance de formular diversas soluções possíveis de serem aplicadas, algumas com sucesso, outras não. O Programa Residência Pedagógica promove a valorização do curso de Licenciatura em Química, a partir do momento em que prepara melhor o Licenciando para o mercado de trabalho".

Quase para a unanimidade dos residentes, a residência pedagógica conseguiu promover uma valorização do curso de Licenciatura em Química, fato observado nas respostas das questões sete e oito, sendo esse um dos objetivos do Programa (BRASIL, 2018). Nesse quesito, acredita-se que a Residência Pedagógica na Licenciatura em Química do IFG, Campus Luziânia, conseguiu desempenhar um bom papel dentro do que se propôs executar.

A nona questão perguntava quais foram os principais motivos que incentivaram o residente a participar do programa. Antes de iniciar as atividades da residência, as principais respostas foram: para a obtenção de horas para atividades complementares, obter experiência em sala de aula, o auxílio financeiro e a possibilidade de convalidar as horas da residência para as disciplinas de estágio. Ao realizar o mesmo questionamento após a participação no programa, as justificativas foram basicamente as mesmas: ter mais experiência no ambiente escolar, pelo incentivo financeiro da bolsa de $\mathrm{R} \$$ 400,00 , aproveitar as horas da residência para atividades complementares e aproveitar a residência pedagógica como horas de estágio supervisionado.

Notou-se que a participação no programa não mudou a motivação dos alunos em ter participado. A experiência em sala de aula é um dos principais objetivos do programa e reconhecer as horas da residência para os estágios supervisionados também é uma indicação do edital (BRASIL, 2018). Além disso, o aproveitamento como horas de atividades complementares também chamou a atenção dos alunos. No curso de Licenciatura em Química do IFG, Campus de Luziânia, os alunos devem cumprir um total de 200 horas de atividades complementares. Caso o aluno não queira aproveitar as horas da residência para os estágios (por já ter concluído os estágios), ele poderia aproveitar como horas de atividades complementares, mostrando um outro incentivo que o programa pode ter. 
Para a décima pergunta do questionário, que indagava o recebimento da bolsa como um dos principais motivos para a participação na residência, antes de iniciar as atividades, $50 \%$ dos alunos justificaram que a bolsa era um dos principais incentivos e, após o término do programa, $50 \%$ dos estudantes continuaram afirmando o incentivo da bolsa. Um diferencial do programa é o auxílio mensal de $\mathrm{R} \$ 400,00$ ao longo dos 18 meses de participação no programa. Este fato não é observado para os estágios supervisionados, que são disciplinas obrigatórias para a conclusão do curso e os alunos não recebem nenhum auxílio financeiro para realizar. Essa justificativa pode tornar a Residência Pedagógica mais atrativa, principalmente em regiões onde boa parte dos graduandos pertencem a grupos sociais com maiores dificuldades financeiras.

$\mathrm{Na}$ décima primeira pergunta, questionou-se se a Residência Pedagógica poderia aperfeiçoar a formação dos futuros professores. Antes de iniciar as atividades do programa, 28 entrevistados (93\%) responderam que sim, nenhum dos entrevistados responderam que não e 02 entrevistados responderam que talvez. Algumas justificativas apresentadas foram:

"Sim, a forma mais eficaz de se aprender é ensinando ou praticando, ao ter contato com a realidade escolar antes da formar";

"Sim, se o residente estiver antenado, trazendo novidades junto com o professor regente, pois não é fácil manter o interesse de um aluno";

"Talvez, acredito que não adianta ter um programa novo para a formação de professores se a educação continuar desvalorizada, sem o investimento necessário";

"Talvez, o contato com a escola pode definir se queremos ou não seguir à docência".

Ao realizar a mesma pergunta após o término do programa, todos os residentes disseram que sim e as principais justificativas foram:

"Com toda certeza. Todo formando almeja sair da graduação com um emprego garantido em alguma escola, todavia a experiência conta muito quando se trata de ministrar aulas e a residência pedagógica pode ser essa maneira de adquirir experiência e aperfeiçoar o que aprendemos em sala de aula"; 
"O contato que o futuro professor tem com a sala de aula, ainda durante a sua formação, permite que esse possa aplicar os seus conhecimentos e ao mesmo tempo aprender com a realidade encontrada. $\mathrm{O}$ discente de licenciatura muitas vezes leva uma nova maneira de ensinar para escola, e nesse ambiente, onde o multiculturalismo está presente, pode-se deparar com diferentes realidades e desafios que devem ser superados"

Após a participação na Residência Pedagógica, todos os residentes afirmaram que o programa contribuiu para o aperfeiçoamento da sua formação, o que era um dos objetivos principais do programa (BRASIL, 2018). Entretanto, alguns alunos lembram que todo esse incentivo para a docência pode ser em vão se não houver uma valorização do professor.

Quanto à décima segunda pergunta (como o Programa Residência Pedagógica pode fortalecer e ampliar a relação entre o IFG e as escolas campo?), antes de participar do programa as principais respostas foram:

"Com interações com os professores das escolas campo, alunos e coordenadores", "Melhorando a formação dos professores de acordo com as necessidades e dificuldades escolares da região";

"Através da inserção dos residentes nas escolas campo que contribuirá para a formação docente auxiliando na aprendizagem dos alunos".

Após a participação no programa, as principais respostas foram:

"O programa já tem fortalecido a relação entre algumas escolas que aceitaram receber os residentes para fazer este trabalho. Quando a gestão se coloca à disposição, ela já demonstra estar preocupada com a formação dos profissionais que possivelmente, um dia, poderão estar ali exercendo a sua profissão como educador";

"As escolas campo podem dar oportunidades, pois sempre tem alunos novos e inexperientes como nós, alguns com medo da sala de aula outros nem tanto. Fazer projetos com a instituição que agregam benefícios para os dois, são inúmeras coisas que tanto o IFG quanto as escolas campo podem fazer para ampliar essa relação".

Fortalecer o elo das Escolas de Educação Básica, onde acontece o trabalho de campo dos futuros professores com as Instituições de Ensino Superior é um dos objetivos do Programa de Residência Pedagógica (BRASIL, 
2018). Entretanto, nenhum residente justificou essa aproximação para os benefícios da pesquisa. Muitas vezes as pesquisas realizadas na IES voltadas para a educação básica não chegam as escolas, como destacado por Pimenta e Lima (2017), e a Residência Pedagógica e os estágios poderiam ser estratégias para fortalecer esses laços e gerar benefícios para a educação.

A décima terceira pergunta questionava se o residente acreditava que o programa Residência Pedagógica poderia proporcionar aos residentes exercitar, de forma ativa, a relação entre teoria e prática profissional docente. Antes de participar do programa, 28 bolsistas (94\%) responderam que sim, 1 bolsista (3\%) respondeu que não e 01 bolsista (3\%) respondeu que talvez. Algumas justificativas apresentadas foram:

"Sim, a teoria e a prática são partes importantes para a formação do professor e precisam caminhar juntas para garantir a eficácia da formação";

"Sim, com a residência acredito que o programa nos auxiliará a ligar a teoria e prática, melhorando o ensino";

"Não, pois o currículo do estado não permite que o aluno da residência mostre tudo o que pode fazer";

"Talvez, só terei essa resposta quando exercer isso na prática".

Após a participação no programa, 25 residentes (96\%) responderam que sim, 1 residente (4\%) que respondeu que não e nenhum respondeu talvez. Algumas justificativas foram:

"a residência pedagógica é uma maneira bastante eficaz de
aliar a teoria e a prática, fazendo com que o residente exercite
muito do que foi visto na graduação, como: planejamento,
planos de aula, gestão e organização do espaço escolar,
metodologias de ensino, entre outros";
"Com certeza, o exercício de forma ativa entre teoria e prática
fica evidente, principalmente a partir do momento em que o
futuro professor passa a participar da rotina da sala de aula, e
é nesse instante em que toda teoria aprendida pode ser
aplicada"; "Não, a prática é muito diferente da teoria".

Mostrar que a teoria e a prática são processos indissociáveis e que devem caminhar sempre juntas é um desafio para os currículos das 
Licenciaturas e também para os estágios (PIMENTA; LIMA, 2017). Entretanto, o programa residência pedagógica poder ser uma alternativa para valorizar que a teoria e a prática não devem ser conduzidas de forma separada, o que pode prejudicar a formação do futuro professor.

A última pergunta do questionário indagava sobre os motivos dos residentes em cursar o curso de Licenciatura em Química. Antes de participar do programa, as principais respostas foram: querer seguir à docência, facilidade de acesso ao IFG, para ter o diploma de curso superior e porque a Química é uma área abrangente e que tem várias possibilidades de emprego em diferentes áreas. Após o término do programa, as respostas obtidas foram basicamente as mesmas das observadas no primeiro questionário. Notou-se que alguns alunos alegaram a facilidade do acesso e apenas ter um diploma de curso superior, sem denotar nenhum interesse pela área ou interesse na para ingressar no curso.

Pelos relatos apresentados, notou-se que, após a realização do programa, a maioria dos objetivos da residência pedagógica foi alcançado, tornando a participação no programa uma etapa de destaque para a formação dos licenciandos.

\section{Considerações Finais}

Com os resultados obtidos e pela comparação dos dois questionários, pôde-se observar que a maioria dos residentes acreditam que o Programa de Residência Pedagógica pode melhorar a qualidade da formação inicial docente, pois o contato mais aprofundado com o ambiente escolar pode proporcionar uma melhor atuação e, principalmente, que por meio da residência pedagógica, os residentes podem exercer a docência de forma ativa. Com isso, observou-se que os objetivos principais deste Programa foram alcançados ao longo das atividades, evidenciando assim sua importância no processo formativo dos futuros professores de Química. 


\section{Agradecimentos}

Os autores gostariam de agradecer a CAPES pelo apoio financeiro.

\section{Referências}

BRASIL. Ministério da Educação. Resolução do Conselho Nacional de Educação - CNE/CP n 2, de 01 de Julho de 2015 - Diretrizes Curriculares Nacionais para a formação inicial em nível superior (cursos de licenciatura, cursos de formação pedagógica para graduados e cursos de segunda licenciatura) e para a formação continuada, 2015.

BRASIL. Coordenação de Aperfeiçoamento de Pessoal de Nível Superior CAPES. Edital CAPES n 06/2018 - Programa de Residência Pedagógica, 2018.

BRASIL. Coordenação de Aperfeiçoamento de Pessoal de Nível Superior CAPES. Edital CAPES n 01/2020 - Programa de Residência Pedagógica, 2020.

IFG. Instituto Federal de Educação, Ciência e Tecnologia de Goiás. Resolução CONSUP/IFG no 31, de 02 de outubro de 2017. Diretrizes Curriculares para os cursos de Licenciatura, 2017.

IFG. Instituto Federal de Educação, Ciência e Tecnologia de Goiás. Projeto Pedagógico do Curso de Licenciatura em Química, 2018.

KASSEBOEHMER, A. C., FERREIRA, L. H. O Espaço da Prática de Ensino e do Estágio Curricular nos Cursos de Formação de Professores de Química das IES Públicas Paulistanas. Química Nova, v. 31, n. 3, p. 694-699, 2008.

LUDKE, M.; ANDRÉ, M. E. D. A. Pesquisa em educação: Abordagem qualitativas. São Paulo: Editora Pedagógica e Universitária, 1986.

PIMENTA, S. G.; LIMA, M. S. L. Estágio e Docência. São Paulo: Cortez. 2004.

PIMENTA, S. G.; LIMA, M. S. L. Estágio e Docência. São Paulo: Cortez. 2017.

SILVA, C. S.; BARBOSA, L. S.; PIRES, D. A. T. A Falta de Professores Licenciados em Química na Educação Básica na Microrregião do Entorno do Distrito Federal e a Perspectiva do IFG para Solucionar tal Problema. Observatório em Debate, v. 2, n. 1, p. 50-67, 2015.

\section{Sobre os autores}

\section{Lilian Ferreira Rocha}

lilyfairy25@gmail.com

Licencianda em Química pelo Instituto Federal de Educação, Ciência e Tecnologia de Goiás (IFG), campus Luziânia. 


\section{Oséias Soares Ferreira}

oseias.soares.ferreira@gmail.com

Mestre em Educação (2018) pela Faculdade de Educação - Unicamp. Graduado em Pedagogia (2010) pela Faculdade do Noroeste de Minas e em História (2007) pela Faculdade DOCTUM. Especialização em História Social e Contemporânea (2018), Educação Profissional Integrada a Educação de Jovens e Adultos PROEJA (2013) e Especialização em Gestão Educacional (2008). Atualmente é Doutorando no Programa de Pós-graduação em Educação da FE - Unicamp (2019). É Professor do Instituto Federal de Educação, Ciência e Tecnologia do Espírito Santo - IFES.

\section{Diego Arantes Teixeira Pires}

diego.pires@ifg.edu.br

Possui graduação em Química (Bacharelado) pela Universidade de Brasília (2010), graduação em Química (Licenciatura) pela Universidade de Brasília (2010), mestrado em Química pela Universidade de Brasília (2012) e doutorado em Química pela Universidade de Brasília (2016). Atualmente é professor do Instituto Federal de Educação, Ciência e Tecnologia de Goiás, campus Luziânia. 